\title{
Pedagogias queer e libertária para educação em cultura visual*
}

Gabriela de Andrade Rodrigues

Universidade de Brasília

Correspndência:

Gabriela de Andrade Rodrigues

Rua Crisântemo, 1. Res. Jardins do

Lago, QD 09

71680-614 - Brasília - DF

E-mail: gabriela.a.rodrigues@gmail.com

\section{Resumo}

Cada vez mais, a escola distancia suas prioridades da formação integral do indivíduo e concentra seus esforços numa preparação econômica dos jovens. Novos modos de ensinar ou a retomada de pedagogias esquecidas podem relembrar os significados primordiais da educação. Na perspectiva de novas maneiras de pensar a educação, encontra-se a pedagogia queer, maneira de educar inspirada na teoria homônima, que analisa e vive a sexualidade e/ou o gênero fluído, não binário. A pedagogia queer não ignora a diversidade das manifestações sexuais, fugindo da maneira binária de entender o gênero e a cultura; é uma educação que traz as diferenças para dentro do cotidiano da sala de aula. Por sua vez, a pedagogia libertária encontra inspiração teórica nos pensamentos e práticas anarquistas de diversos autores, sendo a vertente socialista libertária a mais citada pelos educadores. Os princípios norteadores da pedagogia anarquista são: liberdade, autonomia, criatividade e solidariedade - ademais, a educação integral, que propõe um aprendizado que abarque todos os aspectos do ser humano (intelectual, social, emotivo e motor) e em que os interesses e a individualidade dos estudantes sejam valorizados. Nessa pedagogia, a liberdade é sinônimo de harmonia social. No âmbito da educação em cultura visual, conceito que amplifica o conteúdo geralmente abordado na arte/educação com manifestações culturais contemporâneas e do cotidiano, as novas formas de ensinar possibilitam ao estudante uma maneira menos predeterminada de entender o mundo e a si mesmo.

\section{Palavras-chave}

Pedagogia - Queer - Libertária - Cultura visual - Arte/educação.

*Artigo científico resultante de pesquisa do Programa de Iniciação Científica (PIC/CNPq), sob orientação do prof. Belidson Dias. 


\title{
Queer and libertarian pedagogies for the education in visual culture*
}

\author{
Gabriela de Andrade Rodrigues \\ Universidade de Brasília
}

Contact:

Gabriela de Andrade Rodrigues

Rua Crisântemo, 1. Res. Jardins do

Lago, QD 09

71680-614 - Brasília - DF

E-mail: gabriela.a.rodrigues@gmail.com

\section{Abstract}

The school priorities are growing increasingly apart from the integral formation of the individual, and efforts are being concentrated on the economical preparation of the young. New ways of teaching and the resurgence of forgotten pedagogies can remind us of the primordial meanings of education. Under the perspective of new ways of thinking education we find the queer pedagogy, a manner of education inspired by the homonymous theory that analyzes and experiences sexuality and/or gender as fluid, and not binary. Queer pedagogy does not ignore the diversity of sexual manifestations, but avoids the binary way of understanding gender and culture; it is an education that brings differences into the daily life of the classroom. Libertarian pedagogy finds its theoretical inspiration in the anarchist thinking and practice of many authors, the socialist libertarian movement being the most frequently cited amongst educators. The guiding principles of anarchist pedagogy are: liberty, autonomy, creativity and solidarity - and furthermore, integral education, which proposes a learning that embraces all aspects of the human being (intellectual, social, emotional, and motor), and in which the interests and individuality of the students are valued. In this pedagogy freedom is synonymous with social harmony. Within the sphere of education in visual culture, a concept that widens the contents usually dealt with in art/education with contemporary and daily life cultural manifestations, new forms of teaching afford the student a less predetermined way of understanding the world and him/herself.

\section{Keywords}

Pedagogy - Queer - Libertarian - Visual culture - Art/Education.

* This article results from a research conducted for the Program of Scientific Internship (PIC/CNPq) under the supervision of Dr. Belidson Dias. 
0 presente trabalho propõe mudanças relativas à metodologia de ensino, focando as relações de poder e gênero que cruzam as convivências entre professor/ educando e as socializações entre os próprios estudantes. A pesquisa compõe a ideia de liberdade como constructo social e a rejeição à autoridade instituída, apresentadas pela pedagogia libertária (Gallo, 1995), com as propostas da pedagogia queer, em que o pensamento binário é veemente rechaçado, sem perder um enfoque nas relações identitárias sexuais e de gênero (Louro, 2001).

Ademais, este estudo se localiza na educação em cultura visual, por ser um campo de inúmeras possibilidades interdisciplinares e, mais ainda, um saber que não alcança um estudo aprofundado sem o relacionamento com o social, individual, histórico, filosófico e econômico. 0 conceito de cultura visual expande as possibilidades do conteúdo da sala de aula, ao mesmo tempo que dissolve hierarquias e preconceitos sobre a origem dos objetos (Dias, 2006). A questão é como realizar a difícil tarefa de educar com respeito e liberdade e, mais, como adequá-la à realidade precária do ensino regular público.

\section{Metodologia}

Assim, o presente artigo primeiramente apresenta as duas pedagogias propostas de modo que configure um pequeno panorama de suas origens sociais, principais pensadores e ideias. A apresentação do que significa adotar o ensino em cultura visual também se torna necessária por ser uma proposta recente e fundamental para a utilização das pedagogias citadas. Em conjunto a essa última apresentação, procuro propor atitudes e práticas derivadas da seleção de ideias queer e libertárias que considero pertinentes ao ensino em visualidades.

Procura-se inovar ao relacionar duas metodologias pedagógicas - queer e libertária -, identificando-se seus fundamentos educacionais para propor uma prática educativa mais abrangente, que se detenha sobre mais de um aspecto constituinte do indivíduo. A identificação de pontos complementares entre si - algumas lacunas, ausências ou dúvidas encontradas em uma recebem maior atenção na outra - justificam esse relacionamento. É importante lembrar que a mobilidade e possibilidade de fragmentação de corpos teóricos aparecem como um incentivo à aventura nos modos de ensinar, uma pedagogia para a liberdade - além de ser uma maneira bem queer de encarar o conhecimento (Louro, 2001).

Ressalta-se também a importância de se perceber toda teoria pedagógica como uma proposta e não um dogma, demonstrando que podemos relacionar teses, escolher os pontos com os quais mais nos identificamos e construirmos assim a nossa própria prática pedagógica múltipla e mutável.

\section{Justificativa}

0 ensino regular é organizado pelo agrupamento de jovens em função da quantidade de conhecimento acumulado em relação ao mínimo requerido pelo Estado, por determinado emprego remunerado ou para a admissão em instituição de ensino superior. 0 estudante deve adequar-se às exigências do avanço quantitativo do grupo em que está inserido. 0 aspecto individual do desenvolvimento pode significar um obstáculo nessa corrida pelo ajustamento intelectual, o desenvolvimento corporal pode ficar em segundo plano quando a disciplina física se torna essencial na captação eficiente do conhecimento básico (Foucault, 1987). E, finalmente, a solidificação ética e emocional pode ficar confınada às datas especiais ou a partes do conhecimento menos valorizadas socialmente, consideradas mais disponíveis para lidar com esses temas "secundários" na formação humana.

Foucault (1987) e sua crítica à máquina de ensinar, construída para o adestramento de corpos e mentes e formação de mão de obra eficiente, barata e dócil, foram o ponto de partida para uma pesquisa sobre novas pedagogias e modos de pensar a educação ou 
a retomada de pedagogias esquecidas e pouco praticadas - que podem relembrar os significados primordiais da educação humana. Cada vez mais, a escola distancia suas prioridades da formação integral do indivíduo e concentra seus esforços numa preparação econômica dos jovens. Todos os participantes da ação educacional são parte integrante de um sistema que produz subjetividades (Guattarri, 1993), um padrão de normalidade social coerente com as necessidades de manutenção do status quo. Entretanto, nossas percepções não são imutáveis, e a educação deve desenvolver o processo que desencadeie mudanças tanto em estudantes quanto em professores, ambos afetados pelo mesmo estado social.

Compreende-se que os professores são pessoas que foram e são constituídas dentro de um sistema social desigual, hierarquizado, cheio de ranços e preconceitos. Não se espera que essa prática educacional seja isenta de contradições e falhas, mas sim que o educador aprenda com seus erros, assuma e procure entender seus preconceitos, para assim superá-los e poder, também através do exemplo, construir uma educação mais justa e solidária. 0 risco está presente na relação com seus educandos, que ainda não estão acostumados com novas e diferentes práticas, demonstram muitas vezes resistências. Apesar disso, espera-se que sejam iniciais, que, com o contínuo exercício da liberdade e do respeito, isso se modifique.

Sílvio Gallo (1995) fala-nos sobre a segurança que a falta de liberdade provoca, acompanhada pelo medo do não ajustamento que os métodos punitivos reforçam. Cita Frömm para detalhar as consequências:

Frömm passa depois a detalhar os mecanismos de fuga da liberdade na sociedade moderna, apontando os três principais: o autoritarismo, em que ocorre aquela dissolução do ego no ego coletivo - na perspectiva psicológica - e a abdicação da autoridade para o outro - do ponto de vista político; a destrutividade, uma compulsão psicológica explicada como a tentativa de eliminar o mundo, para não ser eliminado por ele; e o conformismo, que através do alheamento leva a uma vida mecânica, conformada, sem criatividade, que reproduz indefinidamente a "mesmice", sem nenhum comprometimento com a singularidade e com a mudança. (apud Gallo, 1995, p. 171)

Essa postura é facilmente encontrada nas salas de aula, tanto nos educandos, quanto em seus educadores. A importância da utilização de pedagogias arriscadas e inovadoras tornase ainda mais evidente, é necessário que se percorram novos caminhos, que se demonstre a existência destes, pois existe a escolha de direções inusitadas.

\section{Pedagogia libertária}

A pedagogia libertária é uma proposta não acabada, formulada a partir de contribuições teóricas e práticas de vários pensadores anarquistas. Desde o séc. XIX até os dias atuais, escolas livres, práticas libertárias e análises acadêmicas ou autodidatas são produzidas, o que significa um corpo teórico bastante diversificado, que se modificou através dos tempos e que, muitas vezes, apresenta divergências entre seus propositores. Bakunin, Kropotkin e Proudhon são alguns dos principais pensadores anarquistas que contribuíram com análises sobre a educação antiautoritária, a relação educação/revolução e a necessidade de uma educação integral (Gallo, 1995; Préposiet, 2007). A concepção anarquista de educação integral propõe que o aprendizado deve abarcar todos os aspectos do ser humano, que o trabalho intelectual não deve ser separado da prática manual e que a experiência emotiva e corporal não deve ser ignorada (Bakinin, 2003).

0 espanhol Francisco Ferrer y Guardia é um dos grandes expoentes teóricos da pedagogia libertária no Brasil - mesmo que as escolas modernas brasileiras tenham optado pelo caminho da não neutralidade política (Passetti; $\mathrm{Au}-$ gusto, 2008). Paul Robin e o orfanato Cempius 
(1880-84) e Sébastien Faure e a comunidade/ escola A Colmeia (1904-17) foram os grandes exemplos dessa pedagogia posta em prática (Gallo, 1995). Sílvio Gallo é um intelectual e transmissor dessa proposta que se destacou no Brasil. Desse modo, a pesquisa elegeu este último pensador como principal fonte, pela sua proximidade temporal, geográfica e por ter sistematizado um pensamento tão difuso. A pedagogia anarquista apresentada por Gallo segue a corrente socialista-libertária do anarquismo, que defende o mutualismo social, o federalismo e a autonomia individual que não perca o foco do aspecto coletivo da liberdade. Além, é claro, de ser antiautoritária, contra a liderança instituída e todos os tipos de governo (Walter, 2000).

Assim, podem-se identificar Gallo (1995): liberdade, autonomia, criatividade e solidariedade.

De acordo com uma concepção anarquista, a liberdade não é um aspecto natural do ser humano, mas só pode ser entendida e concebida socialmente.

A liberdade não é, pois, um fato de isolamento, mas de reflexão mútua, não de exclusão, mas de ligação; a liberdade de todo indivíduo é entendida apenas como reflexão sobre sua humanidade...

[...]

Só sou verdadeiramente livre quando todos os seres humanos que me cercam, homens e mulheres, são igualmente livres. A liberdade do outro, longe de ser um limite ou a negação de minha liberdade, é, ao contrário, sua condição necessária e sua confirmação. (Bakunin apud Gallo, 1995, p. 25)

A ideia de liberdade como sinônima de harmonia social - diferente da ideia de liberdade individualista, tão difundida na sociedade ocidental desde a Revolução burguesa da França - contraria então o famoso ditado popular de que a liberdade do indivíduo termina quando começa a liberdade do outro; as liberdades caminham e constroem-se juntas, em codependência mútua.
A partir dessa perspectiva de liberdade, o princípio da solidariedade surge como fundamental para o processo educativo. A solidariedade toma um aspecto peculiar nas ideias anarquistas por causa das fortes influências teóricas de Kropotkin (1902) sobre o apoio mútuo, que se opunha às ideias darwinianas de que a sobrevivência só é possível através da luta e da vitória dos mais fortes. Kropotkin propôs que é a "ajuda mútua" que garante a sobrevivência das espécies. Desse modo, fica claro que a pedagogia socialista-libertária não defende um processo educacional irresponsável e sem organização, pois isso significaria uma produção individualista e passiva do conhecimento.

Por outro lado, essa participação ativa só é possível através da autonomia dos participantes do processo educativo, em que a autoridade se torna uma contradição. A autonomia dos estudantes é fundamental para que a criatividade aflore na educação. E se a autoridade do professor é necessária nos anos iniciais do indivíduo (por questões de segurança peculiares à infância), ela tem como objetivo permitir uma segura construção do saber e tem como principal meta a desaparição da dependência intelectual, pois o contrário significaria que a educação fracassou (Bakunin, 1988). Não se pretende aqui atribuir um aspecto teleológico à educação, mas sim reforçar a ideia de que ela é uma preparação para o mundo e que nós educadores não devemos definhar nas disputas de poder e ego do microcosmo escolar.

Louro (1997) discorda das críticas contemporâneas feministas que propõem a negação do poder como solução para os impasses educacionais. "A sala de aula feminista não pode ter conseguido banir as relações de poder simplesmente porque não há espaços livres do exercício do poder!” (p. 116). Certamente a negação do poder não é uma solução, já que isso seria uma postura alienada/alienante da educação. Mas a divisão e (por que não?) dissolução do poder é perfeitamente coerente com o desejo de uma sociedade justa. Por outro lado, uma das principais contribuições da pedagogia libertária é o destaque dado ao exemplo: 
Os educadores, pais e mestres, devem deixar de lado as ordens e afirmações e qualquer forma de sugestão, para valerem-se sobretudo da persuasão arrazoada e da força aprovadora do exemplo; respeitar as atitudes e o ritmo individual do desenvolvimento; usar métodos didáticos que excluam qualquer forma de coerção física e moral, inclusive os castigos, os prêmios, as classificações, os exames, mas capazes de favorecer a autodisciplina, a cooperação, o trabalho em grupo no qual a experiência comunitária não sufoca a iniciativa individual; apresentar, mas não mais com o peso da obrigatoriedade, conteúdos culturais iguais para todos, racionais, científicos, impregnados pela realidade presente, livres de qualquer espírito sectário e nacionalista. (Tomasi apud Gallo, 1995, p. 164)

0 professor detém o poder do conhecimento, mas seu objetivo é perdê-lo, passando esse poder ao estudante. A ambiguidade da autoridade do professor é resolvida se a compararmos com a ideia de representação (quando necessária) por delegados temporários e imediatamente revogáveis do socialismo-libertário (Walter, 2000). Assim, a liderança do professor é necessária pelo acúmulo que possui, mas não deve ser eterna e instituída. Os estudantes muitas vezes possuem conhecimentos exclusivos e, nesses momentos, posições de liderança lhes devem ser atribuídas. Além disso, após o compartilhamento de saberes, não se justifica a insistência sobre a autoridade, que se torna autoritarismo.

Por outro lado, o poder na sala de aula permeia vários outros aspectos: econômicos, raciais, sexuais, regionais, de gênero, geração etc. Um indivíduo está submerso em todos esses aspectos de uma maneira fluida; ao mesmo tempo em que tem poder, é oprimido. Deve-se evitar que o poder pareça natural e imutável, ideia que ignora o silêncio dos indivíduos que não o possuem. Ademais, é essencial a destrinça dos mecanismos de poder para o seu entendimento e subversão. A problematização do poder é necessária tanto em seus aspectos sociais mais gerais, quanto em relação ao poder do próprio professor. A hierarquia nada mais é do que a aceitação do poder da autoridade, mas se há o desejo de uma educação justa e condizente com a formação integral de um indivíduo, ela só pode ocorrer através da desnaturalização de todos os mecanismos opressores (e produtores de hegemonia).

\section{Pedagogia queer}

A pedagogia queer foca o processo educacional nas questões de gênero e sexualidade, mas inova ao incluir sujeitos não normativos nessa perspectiva e rechaçar uma visão binária de poder, conhecimento, sexualidade e gênero. Queer é uma teoria e uma política pósidentitária, causada pelas novas demandas do movimento LGBTTT (lésbicas, gays, bissexuais, travestis, transexuais e transgêneros), influenciada por análises sobre a crise da Aids nos EUA dos anos 80 e pelas teorias pós-estruturalistas de Foucault e Derrida (Louro, 2001; Talburt; Steinberg, 2007). A teoria queer encara a identidade como algo complexo, não fixo e não categorizável - influenciada e formada por todos os aspectos de um indivíduo: gênero, sexualidade, sexo, etnia, geração, classe social, cultura etc. (Louro, 2004, 2008; Talburt; Steinberg, 2007).

0 maior foco de crítica dessa teoria é a normatividade binária que preestabelece formas de viver o corpo, a sexualidade, as performatividades cotidianas. Ao mesmo tempo problematiza os eternos opostos: sexo/gênero, corpo/mente, natureza/cultura, feminino/masculino - que ainda determinam nossas críticas e reflexões sobre a realidade. Butler (2003), a teórica queer mais popular no Brasil, parte da crítica ao pensamento feminista binário para propor uma forma de pensamento e vivência mais "trans", que admita sujeitos e con-

1. Devido ao limite posto à extensão do texto, omitiu-se aqui breve histórico do conceito de raça que constava no texto original, a começar pelas teorias biológicas de raça do século XIX, como o Ensaio sobre a desigualdade das raças humanas, de Arthur de Gobineau, de 1853/55, e Da luta das raças, de L. Gumplowicz, do ano de 1882, cuja influência se manifestou, no Brasil, em obras como História da literatura brasileira, de Sílvio Romero, de 1888, Os sertões, de Euclides da Cunha, de 1902, e Populações meridionais do Brasil, de Oliveira Vianna, de 1920, entre outras. 
ceitos não fixos. São conceitos que questionam e revolucionam noções como fronteira, periferia, transviado e tantos outros que ainda carregam consigo um pensamento binário. A teoria queer propõe mais que uma mudança de termos, propõe uma reviravolta no modo de pensar.

0 grande desafıo não é apenas assumir que as posições de gênero e sexuais se multiplicaram e, então, que é impossivel lidar com elas apoiadas em esquemas binários; mas também admitir que as fronteiras vêm sendo constantemente atravessadas e - o que é ainda mais complicado que o lugar social no qual alguns sujeitos vivem é exatamente a fronteira. (Louro, 2001, p. 542)

A teoria propõe um outro modo de abordar as questões de gênero e sexualidade na sala de aula. Um enfoque não binário significa não posicionar várias identidades como não heterossexuais e, portanto, anormais, que fogem ao padrão. Queer questiona as próprias classificações e como elas acontecem, pois não considera a heterossexualidade como ponto de partida para as outras maneiras de sexualidade, conceituadas como sua negação (Louro, 2001). 0 mesmo ocorre em relação ao gênero: a teoria queer questiona o pensamento feminista que, ao denunciar um sistema patriarcal e machista, necessita de uma definição do ser mulher para a universalidade da luta (Butler, 2003). Esse tipo de pensamento exclui outras formas de se viver os gêneros, pois pressupõe identidades fixas e definidas, além de contribuir para o imaginário dual da opressão/vitimização, que só possibilita dois espaços para se ocupar; é um sistema que pode perpetuar a hierarquia e a exploração ao dar continuidade à análise dialética que o próprio sistema cria para existir (Butler, 2003).

Portanto, as relações de gênero e sexualidade são transpassadas por relações de poder de uma maneira bem mais complexa que a dualista. A teoria queer inclui indivíduos que não querem se encaixar em categorias fixas, que preferem se posicionar de uma maneira "trans", e ao mesmo tempo demonstra que as identidades são compos- tas por vários outros fatores que influem nas relações de poder sexuais e de gênero (Louro, 1997).

Nessa perspectiva, uma pedagogia queer significaria a problematização das questões sexuais e de gênero não tomando a heterossexualidade como ponto de partida, não apresentando as outras inúmeras formas de viver a sexualidade como diferentes do normal ou como algo exótico. Ou seja, não adota uma postura simplesmente politicamente correta, mas apreende que existem múltiplas formas de se viver a sexualidade e o gênero. Entretanto, esse tipo de postura exige uma mudança no pensamento binário e classificatório, já tão incrustado no modo ocidental de entender a realidade. A pedagogia queer toma a proposta de análise desconstrutivista de Derrida e os pensamentos de Foucault sobre sexualidade para entender as relações de poder, os múltiplos aspectos que compõem as identidades, o próprio machismo e a heteronormatividade (Louro, 2001).

A diferença, o problema, deixaria de estar no outro e sim em todos os componentes da questão. 0 feminino também é um gênero como o masculino; por mais que seja difícil estabelecer o que é ser mulher e o que é ser homem, um gênero serve como limite para o outro - homem é aquele que não é mulher - mas e as identidades outras? E a flutuantes? Elas são identidades? 0 sexo representa um componente de predeterminação de gênero? Ou não existe sexo pré-cultural? As identidades normativas são influenciadas pelas consideradas marginais; elas servem para demarcar limites. Assim, a diferença deixa de se pautar pela ausência e sim pela presença, que assombra e desestabiliza. Os jogos de poder tornam-se mais complexos e próximos.

0 pensamento não binário se estende a todo o processo educacional e o próprio conhecimento passa a ser visto como algo fluido. 0 conteúdo de artes, por exemplo, deixa de se pautar pelo dualismo entre as belas artes e todas as outras manifestações, que são contempladas como curiosidades. 0 pensamento flutuante, as discussões e as dúvidas são valorizados em contrapartida às soluções e paradigmas; o que se pretende é entender o naturalizado, os processos e as construções (Louro, 2001). 


\section{Educação em cultura visual}

A mudança do conteúdo geralmente utilizado na arte/educação, de ensino das belas artes para educação em cultura visual, significa mais do que uma mudança nominal. É uma transformação epistemológica. A cultura visual apreende a construção social da experiência visual e por isso desloca o ensino da cultura de elite para a cultura do cotidiano, incluindo outras formas de produção de uma maneira menos hierárquica (Dias, 2006). Entretanto, o ensino da cultura visual não suprime o ensino das belas artes, e sim expande as possibilidades educacionais das artes visuais. 0 conceito de cultura visual possibilita ao estudante uma maneira menos predeterminada de entender o mundo e a si mesmo. Uma das possibilidades da arte é apresentar visões de mundo; a análise e produção dessas visões ajudam a compreender melhor o outro e o eu - e a perceber que as fronteiras não são tão fixas e constantes como pensamos.

Essa inversão é fundamental para a aplicação das propostas queer e libertária na arte/ educação, pois abrange as produções culturais marginais ou consideradas indignas da arte/educação e propõe uma perspectiva transdisciplinar em que a compreensão cultural seja impossível sem a sua contextualização. A utilização da cultura do cotidiano insere o contexto não só como um reflexo na produção artística, mas requer uma visão inseparável das duas perspectivas, influenciadas mutuamente. Além de retirar a produção que foge das especificidades das belas artes da posição exótica ou de momentos especiais, ou ainda da sua reserva para o ensino superior.

Desse modo, é necessário que as artes visuais sejam ensinadas através do pensamento de rede, no qual o que é ensinado não é desligado do cotidiano e da produção contemporânea. Aulas que relacionem o conteúdo obrigatório do ensino médio regular com a arte contemporânea mostram os resultados das influências da percepção moderna e antiga sobre a produção atual - que quebrou e quebra paradigmas da história da arte, ao mesmo tempo em que se apropria dessa história. E também contribuem para o ensino da leitura crítica da produção atual, que apresenta novas formas de materialização, nem sempre confortáveis, pois distantes do ensino escolar e da maioria do público de arte.

A perspectiva da educação em cultura visual, além de propor o estudo de objetos artísticos mais próximos do cotidiano dos estudantes, propõe também uma análise mais contextual que inclui o social e o individual. Ao analisar o contexto social e individual do produtor e perceber a importância desse tipo de análise para o conteúdo da arte, o estudante é levado a analisar o seu próprio contexto social e individual, que pode se aproximar ou não do artista e dos contextos dos outros participantes desse processo educativo. Assim, são abertas possibilidades de entendimento das relações de poder sociais e individuais, de análise dos processos de construção identitária dos próprios estudantes e de inserção de outras identidades para esse entendimento.

Além disso, a proposta de uma educação através da cultura visual é essencial para o deslocamento do estudo de agentes heteronormativos, masculinos, brancos e ocidentais, ainda predominantes nos estudos escolares. 0 reconhecimento de identidades que fogem a essa visão hegemônica ainda é tímido nos relatos históricos artísticos - salvo a produção contemporânea que recebe uma atenção secundária no ensino regular.

A produção artística é também essencial nesse processo. No contexto do Distrito Federal, muitas escolas suprimem a produção dos estudantes no último ano do ensino médio com a justificativa de preparação para o vestibular ou de falta de interesse. Desse modo, infantiliza-se a produção de arte e valoriza-se a expressão intelectual em detrimento da corporal, o que contribui ainda mais para o preconceito que a arte/ educação sofre em relação aos outros saberes. A produção de arte há muito é utilizada como uma maneira de entendimento do próprio corpo, das construções e afırmações identitárias e relações e expressões sociais; seria uma contradição 
confinar essas possibilidades aos que escolhem o estudo da arte como posterior especialização.

Enfım, todas as ideias apresentadas neste artigo se complementam para a realização de uma educação em visualidades realmente comprometida com o desenvolvimento integral do estudante em seus aspectos intelectuais, sociais, emotivos e motores. 0 desenvolvimento expressivo de um indivíduo necessita de um ambiente que respeite sua autonomia e suas escolhas. A criatividade e a solidariedade são modos de viver que estimulam habilidades para um convívio social mais saudável e harmônico. A educação que utiliza a concorrência não auxilia na promoção da autoestima e é um dos maiores mecanismos de disciplina apontados por Foucault (1987) nas escolas - a eterna busca pelo primeiro lugar. A falta de liberdade cria mentes e corpos dóceis, normatizados quanto ao gênero e ao sexo. Ao mesmo tempo, o ranço binário restringe o pensamento a possibilidades predefınidas de análise da realidade e dos próprios conteúdos propostos, formando pensamentos superficiais e pensadores acostumados com a falta de liberdade e criação.

A sala de aula deve ser transformada em um espaço que respeite a individualidade dos estudantes; suas escolhas e processos de desenvolvimento únicos não devem se perder numa ansiosa ditadura da maioria. Para que a autonomia individual consiga se estabelecer, relações solidárias e de ajuda mútua devem ser valorizadas e propostas a todo momento - o saber conviver é mais importante do que aprender a vencer. A criação de espaços para que os estudantes ensinem os conhecimentos que já possuem, mas que muitas vezes não são valorizados na escola, demonstram na prática o respeito a outros tipos de saberes e promove o bem-estar pessoal e coletivo. A criatividade, nesses casos, não fica confinada às possibilidades já preestabelecidas por programas e permite a ação livre e produtiva da aprendizagem. 0 respeito precisa ser cultivado diariamente; saber sobre e promover várias formas de viver - trans ou não - fazem parte do cotidiano. Assim, o respeito ao próximo, a não taxação do exotismo e a discussão aberta sobre todos os temas que surgirem devem ser práticas concretas e sem preconceitos no dia a dia da sala de aula.

\section{Conclusões}

Ao longo do processo de análise das duas pedagogias selecionadas, é visível a importância e complementaridade de ambas. A proposição antiautoritária e por uma liberdade solidária da pedagogia libertária apresenta-se como essencial para a discussão das relações de gênero e sexuais na sala de aula. Por outro lado, a política não binária do estudo do conhecimento e das relações sociais proposta pela pedagogia queer é fundamental para uma construção educativa não hierarquizada. Mostram-se ainda mais relevantes quando direcionadas ao ensino em cultura visual, um saber múltiplo e híbrido.

Mesmo assim, as proposições das pedagogias aqui demonstradas não se resumem aos elementos destacados por esta pesquisa. A pedagogia libertária apresenta ainda considerações quanto às questões administrativas das escolas, o tipo de organização da escola atual, seu relacionamento com o sistema político vigente e o tratamento que as minorias sociais históricas receberam e recebem no ensino regular. A pedagogia queer propõe uma modificação profunda no currículo educacional, demonstrando novas perspectivas ao ensino multicultural. Entretanto, a presente pesquisa procurou fazer um recorte prático tendo em vista a aplicabilidade no ensino regular público, além de introduzir estas propostas ainda pouco conhecidas pelos educadores.

Ao mesmo tempo, estas propostas pedagógicas apresentam uma perspectiva de risco, causada pelas suas características fragmentárias e móveis, não acabadas, e por necessitarem de uma real abertura e participação de todos os agentes do processo educativo - um processo realmente coletivo, mas que não abafe as individualidades.

A teoria que lhes serve de referência é desconcertante e provocativa. Tal como os sujeitos de que fala, a teoria queer é, ao mesmo tempo, perturbadora, estranha e fascinante. 
Por tudo isso, ela parece arriscada. E talvez seja mesmo... mas, seguramente, ela também faz pensar. (Louro, 2001, p. 552)

A visão da educação como um risco, uma aventura, é a tentativa de relembrar seu aspecto de descoberta, do próprio percurso que a humanidade trilhou para construir a cultura - certamente um percurso não linear, não evolutivo e não recebido, mas conquistado, descartado, revisitado, subvertido.

Guacira Louro (2004) retoma a ideia de viagem utilizada tão comumente como metáfora para a educação, ao mesmo tempo que problematiza a perspectiva recorrente de que, após sucessivas aprovações, o pressuposto viajante atinja seu objetivo, finalizando assim uma viagem exterior e interior:

A imagem da viagem me serve, na medida em que a ela se agregam idéias de desloca- mento, desenraizamento, trânsito. Na pósmodernidade, parece necessário pensar não só em processos mais confusos, difusos e plurais, mas, especialmente, supor que o sujeito que viaja é, ele próprio, dividido, fragmentado e cambiante. É possível pensar que esse sujeito também se lança numa viagem. Ao longo de sua vida, na qual o que é importante é o andar e não o chegar. (p. 13)

As pedagogias queer e libertária sugerem a aventura, a liberdade, a não adequação, a criatividade, a experimentação de situações novas, o respeito a sujeitos encontrados no percurso, com histórias e ensinamentos diversos, a autorreflexão e a desconstrução/construção, a permanente mutabilidade de todos os sujeitos envolvidos no processo educativo. Indivíduos cambiantes, que subvertem posições fixas, pensamentos regulados, normas paralisantes e práticas previsíveis.

\section{Referências bibliográficas}

BAKUNIN, M. Deus e o Estado. São Paulo: Cortez, 1988.

. A instrução integral. São Paulo: Imaginário, 2003.

BUTLER, J. Problemas de gênero: feminismo e subversão da identidade. Rio de Janeiro: Civilização Brasileira, 2003. (Coleção Sujeito e História)

DIAS, B. Acoitamentos: locais da sexualidade e gênero na arte/educação contemporânea. Visualidades: Revista do Programa de Mestrado em Cultura Visual da Faculdade de Artes Visuais/UFG, Goiânia: UFG; FAV, v. 4, n. 1 e 2, p. 101-131, 2006.

FOUCAULT, M. Vigiar e punir. nascimento da prisão. Petrópolis: Vozes, 1987.

GALLO, S. Pedagogia do risco: experiências anarquistas em educação. Campinas: Papirus, 1995. (Coleção Magistério: formação e trabalho pedagógico)

GUATTARI, F. Da produção de subjetividade. In: PARENTE, A. Imagem-máquina. Rio de Janeiro: 34, 1993, p. 177-191.

KROPOTKIN, P. Mutualismo: um fator de evolução, sobre o apoio mútuo na natureza e nas sociedades humanas. Inglaterra, 1902. Disponível em: <http://ecosol.noosfero.com.br/kropotkin-e-books-e-livros-e-textos (português)>. Acessado em: 7 maio 2009.

LOURO, G. L. Um corpo estranho: ensaios sobre sexualidade e teoria queer. Belo Horizonte: Autêntica, 2004. Gênero, sexualidade e educação: uma perspectiva pós-estruturalista. Petrópolis: Vozes, 1997. 
Teoria queer: uma política pós-identitária para a educação. Revista de Estudos Feministas, v. 9, n. 2, p. 541-553, 2001. Disponível em: <http://www.scielo.br/scielo.php?script=sci_arttext\&pid=S0104-026X2001000200012\&lng=\&nrm=iso>. Acesso em: 4 out. 2008.

PASSETTI, E.; AUGUSTO, A. Anarquismo e educação. Belo Horizonte: Autêntica, 2008.

PRÉPOSIET, J. História do anarquismo. Lisboa-Portugal: Edições 70, 2007. (Coleção Lugar da História)

TALBURT, S.; STEINBERG, S. R. (Orgs.). Pensar queer. sexualidade, cultura e educação. Mangualde: Pedago, 2007.

WALTER, N. Do anarquismo. São Paulo: Imaginário, 2000.

Recebido em 06.07.09

Aprovado em 22.06.10

Gabriela de Andrade Rodrigues é licenciada em Artes Plásticas pela Universidade de Brasília, educadora social pela Secretaria de Desenvolvimento Social e Transferência de Renda do Distrito Federal e artista plástica - trabalha com xilogravura, instalação e videoarte desde 2006, participando de exposições coletivas. 